\title{
Green Construction: Analysis on Green and Sustainable Building Techniques
}

\author{
Chandra Shekhar Singh* \\ Department of Civil Engineering, Amity University Chhattisgarh, India
}

Submission: January 21, 2018; Published: April 17, 2018

*Corresponding author: Chandra Shekhar Singh, Department of Civil Engineering, Amity University Chhattisgarh, Street 3/B Ashish Nagar (East) Risali Bhilai Chhattisgarh 490006, India, Tel: 9589156841; Email: sshekharsinghh@gmail.com

\begin{abstract}
Green building concept, in broader terms, involves a building, which is designed, built, operated, maintained or reused with objectives to protect occupant health, improve employee productivity, use wisely natural resources and reduce the environmental impact .In other words the green building process incorporates environmental considerations into every stage of the building construction. This process focuses on the design, construction, operation and maintenance phases and takes into account the lot design and development efficiency, energy and water efficiency, resource efficiency, indoor environmental quality, building-owner maintenance and the building's overall impact on the environment. The design of green buildings should thus begin with the selection and use of eco-friendly materials with related or better features than traditional building materials. Building materials are usually selected through functional, technical and financial requirements. However, with sustainability as a crucial issue in the last decades, the building sector, directly or indirectly causing a considerable portion of the annual environmental deterioration, can take up the obligation to contribute to sustainable development by finding more environmentally benign methods of construction and building. Among the directions for solutions is to be found in new material applications, recycling and reuse, sustainable production of products or use of green resources, Careful selection of eco-friendly sustainable building materials may be the fastest way for builders to start integrating sustainable design concepts in buildings. Therefore, Selection of construction materials that have minimum environmental burdens is useful in the sustainable development of a nation. The purpose of this paper is to highlight how sustainable building material can contribute to lessen the impact of environmental degradation, and generate healthy buildings which can be sustainable to the occupant as well as our environment.
\end{abstract}

Here it it's a small concept is presented in the paper to save environment \& energy conservation: GREEN CONSTRUCTION CONCEPT. This concept will be a major step for the building sector for eco friendly design on energy \&environmental concerns.

Keywords: Green building; Sustainable development; Modern building techniques; Cost efficiency; Environment friendly

\section{Introduction}

The term "Green" refers to environmentally friendly practices from building design to the landscaping choices. It also optimist \& Economic energy use, water use, and storm water and west water reuse. The term "Green Building" applies not just to products, but to construction strategies, building design and construction practice and promotes the economic health and well-being of your family. The community and the environment. A smart step toward personal economic rewards, green building has positive social and environmental ramifications that assert your commitment to the future and the way we live for years to come Buildings have a tremendous impact on the environment, using about $40 \%$ of natural resources extracted in industrialized nations, consuming virtually $70 \%$ of electricity and $12 \%$ of potable water, and producing between $45 \%$ and $65 \%$ of the waste disposed in our landfills. Additionally, they are responsible for a massive amount of harmful emissions, accounting for $30 \%$ of greenhouse gases, due to their operation, and an additional $18 \%$ induced indirectly by material Exploitation and transportation. Simultaneously, the bad quality of indoor environments may result in health issues to employees in office buildings, hence, reducing efficiency [1-3].

From the environmental impact perspective, the building sector has a significant effect on the entire environment. Residential buildings represent a large percentage of the built environment, and the selections of materials and layouts are necessary for the general sustainability. Considerable initiatives have been carried out by the research community worldwide, in order to find alternative sustainable building materials and low technology methods, which result in a more sustainable and affordable construction adhering to the comfort standards needed today. Adopting green building materials is an excellent approach to meet this target. Selection of construction materials which have minimum environmental burdens is useful in the sustainable development of a country. Therefore, 


\section{Civil Engineering Research Journal}

building related contribution to environmental issues is large and therefore essential. Selecting environmentally preferable building products is an excellent method to boost a buildings environmental performance. While there is obviously an immediate need for new technologies to optimize the application of low-impact building materials, it is also true that there are several technologies or systems, currently in use. Many have originated from an earlier influx of sustainable housing activism and development, prompted by the 1970s environmental movement, and then boosted by the force for better energy efficient buildings. their strategy has been referred to as effective in spreading ideas about best practice to dedicated green advocates, builders and individuals seeking for an alternative means of determining the material-selection process, very few such systems are available that support the effective and substantial use of local and recycled building materials in the design-decision making phase of a building [4-7].

During the last 30-40 years we have been sensing the bitter experience of global warming, ozone depletion, resource depletion, energy scarcity, ecological toxicity, human toxicity, acid rains etc. These have alarmed, rather compelled the mankind to change the way they operate on the earth. Though we cannot avoid affecting the environment, the green buildings will aim and contribute towards minimising the environmental impact. It should also be emphasized that green buildings do not only contribute towards a sustainable construction and environment but it also brings lots of benefits and advantages to the building owners and the users. It contributes towards lower development costs lower operating costs, increased comforts, healthier indoor environment quality, and enhanced durability and less maintenance costs. The uncertainties in application of green building concept Though there are guidelines being developed for implementation of green building concepts, there are many gray areas and unfolded chapters which hinder the success of their implementation. The most significant fact being that there is very little publicly available data regarding manufacturing process that document energy consumption, impact on natural resources, $\mathrm{CO}_{2}$ emissions for each building material etc. Therefore, undoubtedly, to a certain degree [8].

\section{Methodology}

\section{Factors to consider}

Lot design, preparation and development: Thoughtful and efficient site design and development practices help lessen environmental impact and improve the energy performance of new Constructions. The designs with a focus on saving trees, constructing onsite storm water retention/infiltration features and orienting the house to maximise solar power gain are basic aspects in a green building [9].

Resource efficiency: It is a fact that a green building is most successful when the concepts are incorporated and implemented at the design phase-the time at which material/product/ system selection occurs. Creating resource efficient designs and using resource efficient materials can maximize function while optimizing the use of natural resources. For instance, engineered wood products can help optimize resources by using materials in which more than $50 \%$ more of the log is converted into structural timber than conventional dimensional timber. But we need to weigh the benefit of such products against the amount of energy consumed during the process and accordingly make our selection. One aim of resource efficient construction is to reduce job-site waste. Invariably, there are leftover materials from the construction process. Adhering to a construction waste management plan helps reducing the quantity of landfill material. This can be achieved through taking advantage of available recycling facilities and markets for recyclable materials. This will help reducing the construction waste by at least twothirds, creating potential cost savings for builders and reducing the burden on landfill space [10-12].

Energy efficiency: The energy efficiency is weighted heavily in most green building programs. A whole system approach will bring improved results. Further, a careful window selection, building envelope air sealing, duct sealing, proper placement of air and vapour barriers, use of solar powered heating/cooling systems will contribute towards an energy efficient building.

Water efficiency: Green homes often focus on conserving water both indoor and out. Implementing more efficient water delivery system indoors and native and water retaining and drought resistant landscaping selections outdoors can aid preventing unnecessary waste of valuable water resources. For an example use of heavy and light water-closet flushing options (implemented in The Tea Factory Hotel located in Nuwaraeliya in Sri Lanka) will help conserving water used indoor. Current research and practices have shown the natural processes can be a very successful method of filtering and removing contaminants from storm water and waste water which can then be reused successfully for irrigation purposes etc [13].

Indoor environmental quality: An increase in respiratory ailments and allergies and the use of chemicals that can give off gas from materials have greatly contributed to sensitive awareness of the air we breathe inside our homes. The green building focuses on measures that can lessen the effects of potential contamination including controlling the source, diluting the source, and capturing the source through filtration. Operation, maintenance and building owner educationImproper and inadequate maintenance can hamper the designers' and contractors' efforts to create a resource efficient environmental friendly building. By educating owners with alternative environmental friendly products/systems for use in maintenance of buildings and providing owners with an effective and proper operation and maintenance manual may help obtaining their contribution to achieve green building objectives [14]. 


\section{Civil Engineering Research Journal}

\section{Green Building Features}

Green building has many stark features. Some of them are:

o Energy efficient equipment for air conditioning and lighting systems and use of onsite renewable energy

o Measurement and verification plan to ensure energy \& water savings

o Reduction of building footprints to minimize the impact o environment.

o Minimal disturbance to landscapes and site conditions

o Use of recycled and environmental friendly building materials.

o Use off non toxic and recycled/recyclable materials.

o Efficient use of water recycling

o Indoor air quality improvement for human safety and comfort

o Use of rapidly renewable materials

o Providing day light for visibility (Figure 1).

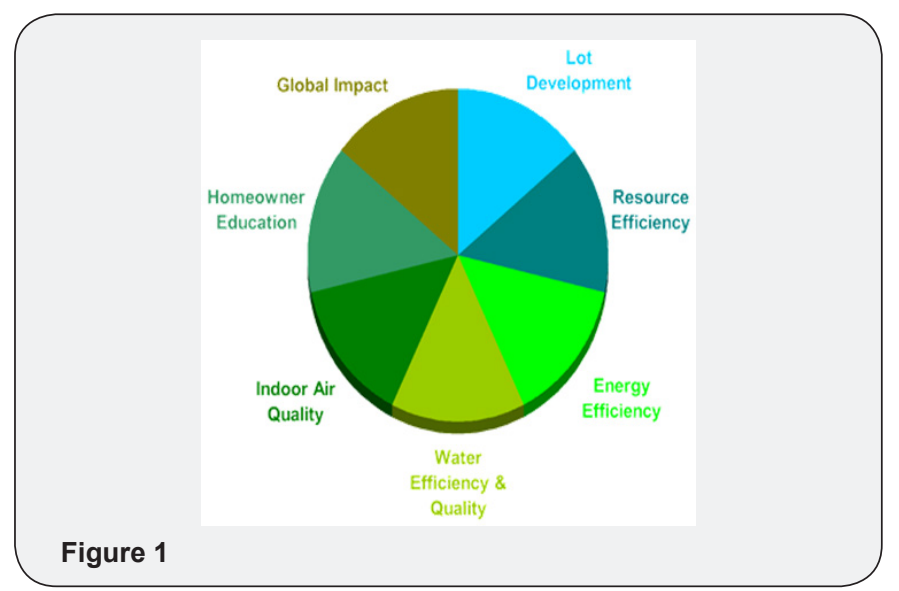

Energy (Efficiency) in Green Building

For a new or renovated building to achieve energy efficiency, make sure to include these three steps:

o Use a comprehensive integrated design process, also called Integrated Project Delivery

o $\quad$ Establish goals, targets, and strategies

o Implement energy efficiency measures holistically

The key to energy efficiency in new buildings or renovations is to have a comprehensive integrated perspective during the design phase that seeks to:

o Reduce heating, cooling, and lighting loads through taking advantage of the building site and climate attributes. Include passive solar design and integrated landscape design that use trees for shading, windbreaks, and attractive outdoor spaces. o Research and include renewable energy sources such as day lighting, passive solar, solar thermal (hot water) and photo volts, and geothermal heating and cooling. Use of renewable energy increases energy security and reduces dependence on fossil fuels.

o Use project specifications to lay the groundwork for energy efficiency, specifically stating project goals, targets, and strategies for energy efficiency. Specify energy efficient HVAC equipment that meet or exceed federal, state, and local standards, such as LEED, Energy Star, or other federal or state high-performance mandates.

o Increase building performance by including predictive energy models and system controls, such as occupancy and daylight sensors, $\mathrm{CO}_{2}$ sensors and other air quality alarms. Employ sensors that control loads based on occupancy and availability of natural resources such as daylight or natural ventilation. Use energy management tools to track energy and water use such as the Energy Star Portfolio Manager.

o Integrate water saving technologies that reduce the energy burden that comes along with providing potable water such as Water Sense fixtures and rainwater harvesting practices.

Measure and verify that the predictive model and energy efficiency goals were met. Green design can help to give you a healthy and efficient house that is also environmentally friendly and you money in the long term [15].

Orientation to the sun to take advantage of passive solar heating and lighting

o Build an energy efficient structure, creating a well insulated envelope that requires less energy to heat and cool.

o Low E windows to prevent the loss of heat.

o Green materials. Lumber from sustainable forestry practices, material that emit low toxins, recycled materials and water saving faucets.

o Use of advanced energy systems geothermal heating/ cooling masonry heater, photovoltaic cells, solar hot water and wind turbines.

\section{Material Selection}

Use of toxic substances in the construction may be harmful to the overall health of a building's occupants. In spite of an increasing awareness of the environmental health problems regarding exposure to a number of products, there is little focus in reality schools on picking materials based on their potential for out gassing harmful chemicals, demanding regular maintenance with such chemicals, or requiring regular replacements that perpetuate the exposure cycle. Evaluation of building products, from the gathering of raw materials to their ultimate disposal, 
gives a better perception of the long-term costs of materials. These costs are paid not merely by the client, but also by the owner, the occupants, and the environment. The principles of Life Cycle Design offer essential guidelines for the selection of building materials. Every phase of the manufacturing process, from gathering raw materials, manufacturing, distribution, and installation, to ultimate recycle or disposal is inspected for its environmental impact. A material's life cycle could be well organized into three stages, Pre-Building, Building, and PostBuilding. These stages parallel the life cycle phases of the building itself. The assessment of building materials' environmental impact at every phase enables a cost-benefit analysis over the lifetime of a building, instead of merely an accounting of initial construction costs [16].

\section{The pre-building stage}

The Pre-Building Stage explains the production and delivery process of a material up to, but not including, the point of installation. This consists of finding raw materials in nature as well as extracting, manufacturing, packaging, and transportation to a building site. This particular stage has the most possibility of creating environmental destruction. Knowing the environmental impacts in the pre-building phase will result in the wise selection of building materials. Raw material procurement methods, the manufacturing process itself, and the distance from the manufacturing location to the building site all have environmental implications. An understanding of the beginning of building materials is vital to an understanding of their collective.

\section{The building stage}

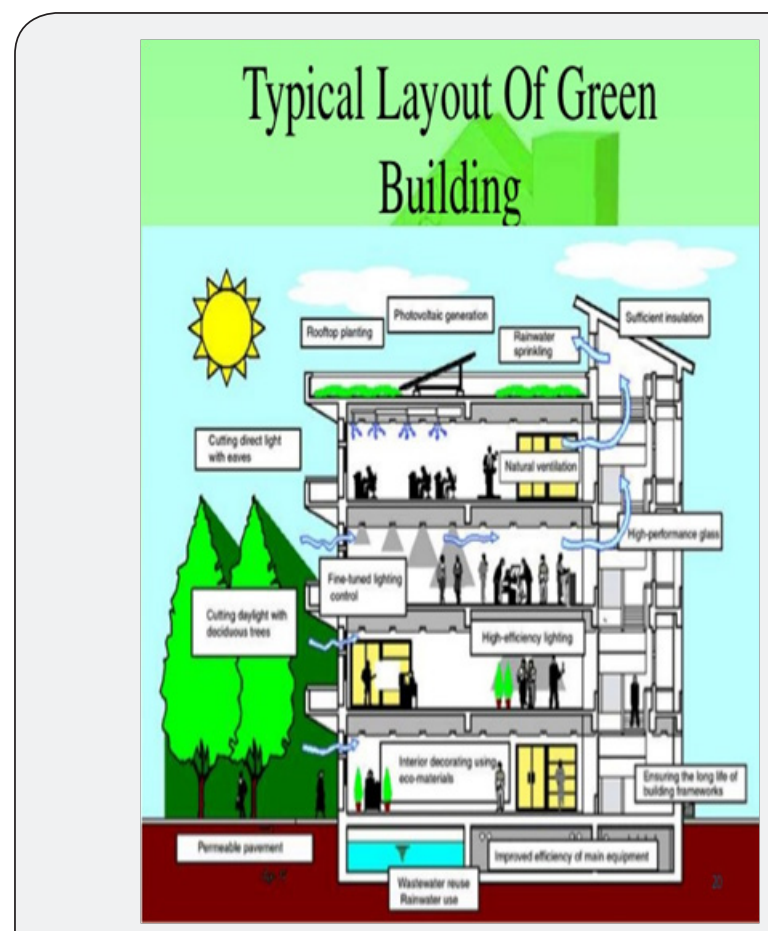

Figure 2: Typical Layout of Green Building.
The Building Stage refers to a building material's useful life. This stage commences at the point of the material's assembly into a structure, involves the maintenance and repair of the material, and goes all over the lifetime of the material within or as part of the building. The material waste generated on a building construction site can be considerable. The selection of building materials with regard to minimized construction waste, and waste that can be reused is crucial on this stage of the building life cycle. Long-term exposure to specific building materials (Figure 2).

\section{The post-building stage}

The Post-Building Stage refers to the building materials when their performance in a building has run out. At this stage, a material could possibly be recycled in its entirety, have its elements reused back into other goods, or perhaps be thrown away. From the perception of the designer, perhaps the minimum measured and least recognized stage of the building life-cycle occurs when the building or material's useful life has been exhausted. The demolition of buildings and clearance of the resulting waste has a substantial environmental cost. Degradable materials may generate harmful waste, alone or even in mixture with many other materials. Inert materials consume gradually scarce landfill space. The adaptive recycle of a present structure sustains the energy that went into its materials and construction. The energy embodied in the construction of the building alone and the manufacture of these materials will be wasted if these resources are not effectively utilized.

\section{Principles of Sustainable Building Design}

\section{Healthy interior environment}

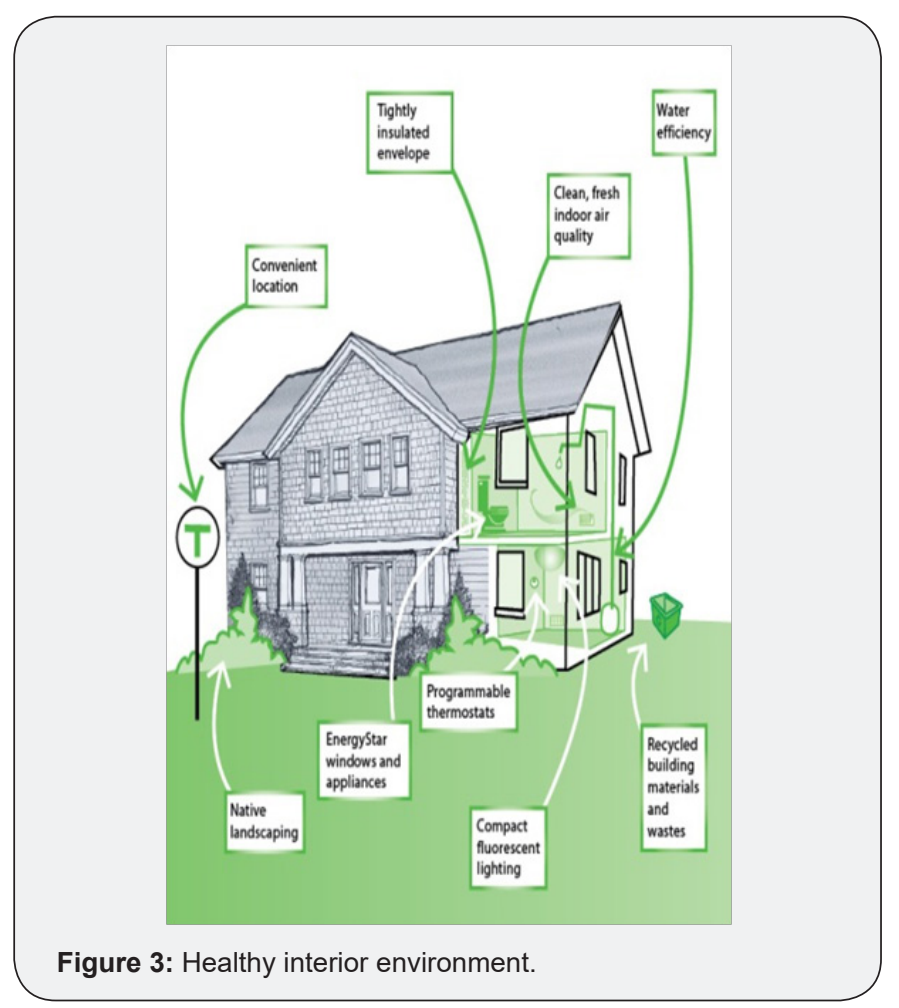


All possible measures are to be taken to ensure that materials and building systems do not emit toxic substances and gasses into the interior atmosphere. Additional measures are to be taken to clean and revitalize interior air with filtration and planting (Figure 3).

\section{Energy efficiency}

All possible measures are to be taken to ensure that the building's use of energy is minimal. Cooling, heating, and lighting systems are to use method and products that conserve or eliminate energy use.

\section{Ecologically benign materials}

All possible measures are to be taken to use building materials and products that minimize destruction of the global environment.

\section{Environmental form}

All possible measures to be taken to relate the form and plan of the design to the site, the region, and the climate. Measures are to be taken to relate the form of building to a

\section{Good design}

All possible measures are to be taken to achieve an efficient, long lasting, and elegant relationship of use areas, circulation, building form, mechanical systems and construction technology.

\section{Future Challenges}

In order to mitigate the effect of buildings along their life cycle, Green Building (GB) has become a new building philosophy, pushing the application of more environmentally friendly materials, the implementation of strategies to save resources and lower waste consumption, and the improvement of indoor environmental quality, among others. This might lead to environmental, financial, economic, and social benefits. For instance, savings in operation and maintenance costs in GBs can be realized through the installation of high-efficiency illumination and insulation systems or through a suitable material selection process that considers, for example, the daylight roof reflection. Other primary advantages of GBs related to indoor environmental quality advancements are the reduction on health costs and the increase on employees' productivity through their perceived satisfaction towards work areas. Furthermore, intangible benefits, such as the building and builder's goodwill, and perceived added value must also be considered simply because they could guide the decisions of investors and future owners. Despite their demonstrated benefits, GBs are not yet regarded as attractive projects since most builders relate green features with expensive technologies that increase cost (e.g., photovoltaic panels, grey water reuse systems). Nevertheless, a careful design process and a comprehensive material selection method, rather than an elevated investment in technology, may be sufficient to accomplish ideal environmental objectives at a lower cost. In reality, some research supports the insufficient difference between the average investment cost per square foot for some GBs, such as academic buildings, laboratories, community centres, and ambulatory care facilities, and that of non-green buildings with the same characteristics. Moreover, GBs provide better dividends in the long run recovering up to 10 times the green premium through the realization of anticipated benefits. The achievements of a GB will depend on the quality and effectiveness of the installed green systems. Therefore, the market demands a common approach to distinguish GBs from traditional buildings through the use of standard, transparent, objective, and verifiable measures of green that will ensure that the minimum green requirements have been achieved [17].

The material challenge for buildings usually takes various forms. As stated, the grey energy and emissions must be regarded, and the production of building materials involves the use of more high value energy and resources in comparison with building operations. There are also environmental issues with the by-products of material used in buildings, and there are limitations on the extraction of resources used in numerous building ingredients. One should additionally consider the infrastructure used to support the built environment.

There are lots of technological advances that need to be carried out to resolve the complications of resource depletion, corrosion, pollution, durability, lifespan, etc. related to building materials. Firstly, new construction needs to be constructed more sustainably so that it not just reduces negative aspects of construction and operations, but that it primary boosts building lifespan, which can be carried out by eliminating design features that will be rapidly outdated. Also all required factors with minimal life spans should be designed for recycle or raw-material-recovery. This must be attained in all aspects by carefully breaking down the complexity of the building into its components, and comprehending virtually any trade-offs among integrated systems so that a completely sustainable solution can be achieved. This can be assisted by an awareness of the rapidly growing array of materials readily available for build structures.

Lastly, with regards to the end of lifetime of a building, there needs to be extremely careful consideration for the processing of the materials. This should be considered previously during the design stage of any building, where composites that are hard to handle are minimized. Materials should be used that can be immediately recycled without the need to remanufacture them. If they cannot be immediately reused, they can be recovered as raw materials. If they should be reused, they should be utilized at the same level.

\section{Conclusion}

As the build account for the $40 \%$ of the global carbon emission, the green construction techniques have an unprecedented opportunity to make a major contribution to new global carbon reduction targets. The common carbon metric will be piloted by the green building rating tools. 


\section{Civil Engineering Research Journal}

The mankind hasimpacted so much on the global environment to twist its balance. Therefore, today, as the dependents of the environment, at whichever level in the society you and I are, it is a timely obligation of us to wide open our eyes towards changing our attitudes and the way of living. Begin individual, think simple and light but apply heavily, when need one, use only one not two, impart the accrued benefits/losses with the person next to you and contribute towards a sustainable environment.

Materials which are domestically created and sourced which decreases transportation costs and $\mathrm{CO}_{2}$ emissions, they could consist of reused materials, they possess a lower environmental effect, they are thermally effective, they need less energy than conventional materials, they make use of renewable resources, they are lower in harmful emissions and they are economically sustainable. A sustainable building material needs to be used properly and contextually in every community development. The application of sustainable building materials not just minimizes transport costs, carbon emissions, and in most cases materials costs, it also offers employment and skills development opportunities for community members.

\section{References}

1. Diana Gutierrez (2018) How Do Green Building Principles Support Energy Efficiency? Straughan Environmental, USA.

2. Indunil D. Batuwangala (2018) An Overview of the Green Building Concept. Dubai.

3. Pulselli RM, Simoncini E, Pulselli FM, Bastianoni S (2007) Emergy analysis of building manufacturing, maintenance and use: building indices to evaluate housing sustainability. Energy and Buildings 39(5): 620-628.

4. Wang W, Zmeureanua R, Rivard H (2005) Applying multi-objective genetic algorithms in green building design optimization. Building and Environment 40(11): 1512-1525.
5. Yudelson J (2008) The green building revolution. Washington DC: Island Press.

6. Venkatarama Reddy BV, Jagadish KS (2003) Embodied energy of common and alternative building materials and technologies. Energy and Buildings 35(2): 129-137.

7. Ries R, Bilec M, Gokhan NM, Needy KL (2006) The economic benefits of green buildings: a comprehensive case study. The Engineering Economist 51(3): 259-295.

8. Cooper I (1999) Which focus for building assessment methods: Environmental performance or sustainability? Build Res Inf 27: 321331.

9. Thormark C (2006) The effect of material choice on the total energy need and recycling potential of a building. Building and Environment 41(8): 1019-1026.

10. Ross B, Lopez-Alcala M, Small III AA (2007) Modeling the private financial returns from green building investments. Journal of Green Building 2(1): 97-105.

11. Moeck M, Yoon JY (2004) Green buildings and potential electric light energy savings. Journal of Architectural Engineering 10(4):143-159.

12. Edwards B (ed.) (2003) Green buildings pay ( $\left.2^{\text {nd }} e d n\right)$. New York: Spon Press, USA.

13. Kats G (2003) The cost and financial benefits of green buildings: a report to California's sustainable building task force. Sacramento, CA: Sustainable Building Task Force.

14. Muse A, Plaut JM (2006) An inside look at LEED: experienced practitioners reveal the inner workings of LEED. Journal of Green Building 1(1): 3-8.

15. Baker G (2006) Certification impacts private sector. Environmental Design and Construction 9(6): 80-82.

16. Matthiessen LF, Morris P (2007) The cost of green revisited: reexamining the feasibility and cost impact of sustainable design in the light of increased market adoption. Davis Langdon.

17. Sherwin D (2006) Reducing the cost of green. Journal of Green Building $1(1): 46-54$
This work is licensed under Creative

Commons Attribution 4.0 License

DOI: 10.19080/CERJ.2018.04.555638
Your next submission with Juniper Publishers will reach you the below assets

- Quality Editorial service

- Swift Peer Review

- Reprints availability

- E-prints Service

- Manuscript Podcast for convenient understanding

- Global attainment for your research

- Manuscript accessibility in different formats

( Pdf, E-pub, Full Text, Audio)

- Unceasing customer service

Track the below URL for one-step submission https://juniperpublishers.com/online-submission.php 